\title{
Intra Osseous Arteriovenous Malformations of Hand and Foot: Treatment Outcome after Open Surgical Cementoplasty in 9 Patients
}

\author{
Claude Laurian ${ }^{1 *}$, Annouk Bisdorff², Veronique Marteau², Claudine \\ Massoni $^{3}$, Claudine Pierre Cerceau ${ }^{4}$ and Emmanuel Houdart ${ }^{2}$ \\ ${ }^{1}$ Department of vascular surgery Saint -Joseph Hospital Paris, France \\ ${ }^{2}$ Department of neuroradiology Lariboisiere Hospital, France \\ 3Ultrasonography Center, France \\ ${ }^{4}$ Department of vascular surgery Bichat Hospital, France
}

Research Article

Volume 3 Issue 4

Received Date: October 06, 2019

Published Date: October 29, 2019

DOI: $10.23880 /$ jobd-16000189

*Corresponding author: Claude Laurian MD, Department of vascular surgery Saint -Joseph Hospital Paris, 189 rue R. Losserand Paris 75014, France, Tel: +33617319157; Email: cl.laurian@gmail.com

\section{Abstract}

Background: To evaluate the benefit of open surgical cementoplasty on the intra osseous nidus in the treatment of arteriovenous malformations (AVMs) on hand and forefoot.

Methods: Over the period 2014-2017, 9 consecutive patients underwent open cementoplasty of bone for AVMs of hand and foot. Investigations included digital radiography, Doppler ultrasound, and CT scan with bone and vascular reconstructions. The main outcome end points of this study were: pain, residual AVMs identified by CT scan, and quality of life.

Results: Over a period of 4 years, 65 patients with AVM on hand (38 pts.) or foot (27 pts.) were observed in our institution, 10 pts. (15\%) of the cohort had bone involvement.

Nine patients (4 F, $5 \mathrm{M}$ ) with a mean age of 30 years (range 10-50) were included in this study. On their hand (n=5), skeletal changes were at first metacarpal (2pts), in the proximal and middle phalanx ( 3 pts.). On their foot ( $\mathrm{n}=4)$, changes were in the metatarsal ( 3 pts.), in proximal and distal phalanx ( 3 pts.). Nine patients had a targeted cementoplasty of the involved bone. On control CT scan, 9 patients had no residual intraosseous AV shunts, 4 had minor shunt around bone. Mean follow-up was 29 months (range 10-55 m). No morbidity, no delays of healing were observed. Disappearance of pain was the dominant impact in all the patients.

Conclusion: Open surgical cementoplasty is a new option for AVMs bone lesions located in the digits and forefoot. The conclusions are restricted by the short period of follow-up.

Keywords: Arteriovenous Malformations; Intraosseous; Cementoplasty; Surgery 


\section{Journal of Orthopedics \& Bone Disorders}

\section{Introduction}

The treatment of peripheral arteriovenous malformations (AVMs) remains the most challenging among other vascular malformations. Minimally invasive embolization techniques or invasive surgical treatment are the two options for symptomatic lesions with their own limit. Various classifications have been proposed to define the best strategy and to compare results [1-4]. Classifications were based on: clinical presentation, affected areas, or angioarchitecture of the AV shunt. None of them took into consideration the possible intra-osseous $\mathrm{AV}$ shunt determined by digital radiography and CT scan. AVMs can be located only in the bone, or can be associated with soft tissue involvement $[5,6]$.

The aim of this study was to analyze benefits of open cementoplasty in terms of: pain, residual AVMs as identified by Doppler US and CT scan, and functional results.

The hypothesis was to demonstrate that the cementoplasty was a more efficient procedure to treat intraosseous $\mathrm{AV}$ shunts than arterial or venous embolization.

\section{Methods}

\section{Study Design}

This study was retrospective, observational, mono centric.

A total of 9 symptomatic patients (selection based on our interdisciplinary evaluation) were included in this study over the period 2014-2017. The surgery was performed or supervised by a single surgeon.

All patients or family were provided with oral and written information about surgery and they provided consent. Asymptomatic or limited symptomatic patients were excluded from this study.

\section{Data Collection}

All data were collected from each patient's medical record and included: medical history, previous treatments, examination findings, imaging results and assessment scores for the quality of life. Further information regarding surgical procedures: intraoperative blood loss, postoperative morbidity and surgery time were also collected.
The quality of life was determined by using a clinical score defined by our Institution for pain, residual symptoms related to the pathology. Pain was rated on the scale of 1 to 3 in the preoperative period, at 6 months and at the last follow-up (1: minimal to no pain, 2 intermittent pains, and 3 permanent pains). The score for residual symptoms was based on the hand on scale of 1 to 3 (1: normal digital mobility, 2: limited mobility/reduction muscular strength, 3: minimal/no use of hand), for the foot (1: normal walk, 2: difficult on wearing shoes and 3: intermittent or permanent limp).

\section{Clinical Protocol}

Patients were selected due to their persevering symptoms following medical treatment (elastic garment, beta blocker drug, pain killer), or after lack of improvement after embolization.

Non-invasive investigations included digital radiographs, Doppler US, CT scan with osseous and vascular reconstruction (Figure 1). A preoperative embolization was not decided at this time due to the distal location of the nidus.

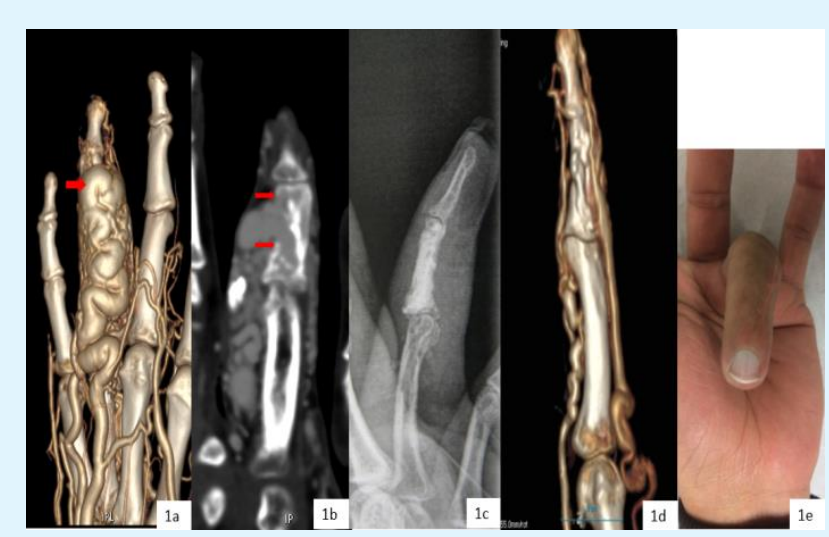

Figure 1: AVM of the 4th finger in 33 years-old adult manual worker.

a- CT vascular scan: ectasic venous drainage down intra osseous shunt in front of P2 (arrow).

b- Initial CT scan: venous drainage through the cortical defect, developed in subcutaneous tissue (arrow).

c- Radiographic control after cementoplasty

d- Control CT scan at 6 months: no AV shunts in P2, residual micro shunts in $\mathrm{P} 3$

e- Functional result at 12 months, normal mobility of the digit. 


\section{Journal of Orthopedics \& Bone Disorders}

\section{Surgical Technique}

A dorsal approach of the bone involved was used the side where venous drainage was not dominant. The dorsal part of bone was exposed in respect of the venous drainage, and after mobilization of tendinous extensor digitorum longus. A tourniquet was inflated around the patient's systolic arterial pressure and the diaphysis area was opened with a sized cortical trapdoor of $20-30 \mathrm{~mm}$ to $6 \mathrm{~mm}$ wide.

Then the entire metaphysis and diaphysis was drilled to obtain a space of all length of bone, the cortical feeders'orifice and the cortical defect of the draining vein well identified. The bone has been filled by cement to obtain occlusion of cortical defects and the cortical trapdoor covered (Figure 2). Following the release of tourniquet, the hemostasis was usually perfect, the trapdoor was covered by the tendon and incision has been closed. Immobilization was required for 2 days.

6-12 months following the surgery, control Doppler US and CT scan were performed. Residual soft tissue AVM around the bone was scheduled for surgical resection after a delay of 6 months. Then, patients were followed-up each 6 months in our institution.

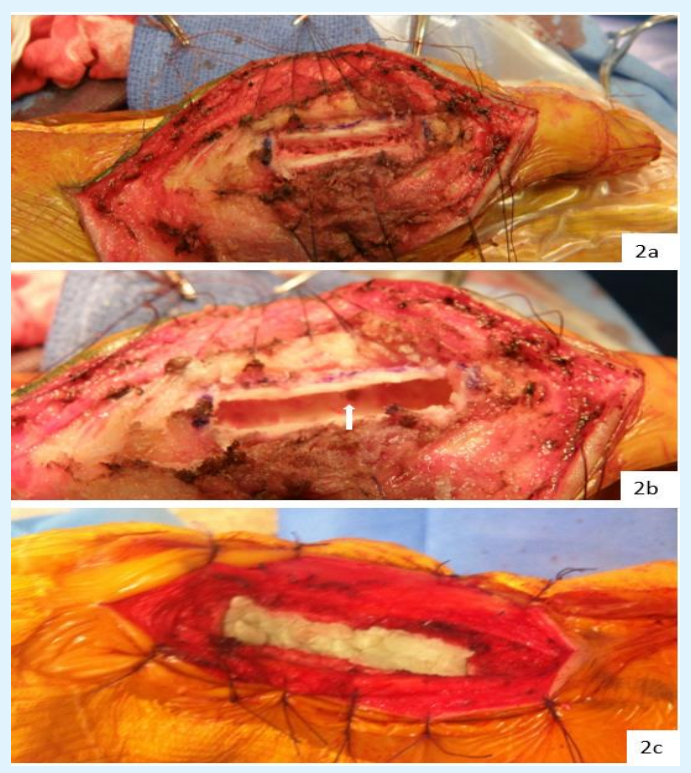

Figure 2: Intramedullary bone cementoplasty: operative views a- Cortical trapdoor on the metaphysis of first metacarpal, perfect hemostasis obtained by tourniquet b- Drill of the medullary cavity. In the opposite cortical, see orifice of cortical afferent artery (arrow) c- Cement fills diaphysis and part of the metaphysis, no hemorrhage after release of tourniquet.

\section{Results}

\section{Clinical Information}

Open cementoplasty for AVMs of hand and foot was performed on 9 patients between 2014 and 2017 (4 females, 5 males with a mean age of 30 years (10-50)). 4 of these 9 patients underwent previous arterial embolization (4pts 1 to 3 sessions), 2 of them had partial surgical resection without improvement.

Patients were symptomatic: intermittent pain (6 pts.), permanent (1 pt.), ambulation difficulty (4 pts., toe's $A V M)$, recurrent hemorrhage (2 pts.) (Table 1). It is worth noting that on 2 patients, we identified symptoms appearing after pregnancy. 


\section{Journal of Orthopedics \& Bone Disorders}

\begin{tabular}{|c|c|c|c|}
\hline Patients & Previous procedures & Symptoms & Localization \\
\hline \multicolumn{5}{|c|}{$\mathrm{N}^{\circ}$ /gender /age } \\
\hline \multicolumn{5}{|c|}{ HAND } \\
\hline 1/M/34 & - & Pain limited function & 1rstdigit - 1rstmetacarpal \\
\hline $2 / \mathrm{M} / 50$ & - & Pain swelling & 1rstdigit - 1rstmetacarpal \\
\hline $3 / \mathrm{F} / 33$ & - & Pain swelling & 1rstdigit - 1rstmetacarpal \\
\hline $4 / \mathrm{M} / 33$ & A.E. 1 session & Pain & 4thdigit - 2nd phalanx \\
\hline $5 / \mathrm{F} / 22$ & - & FOOT & 3thdigit - 1rstphalanx \\
\hline \multicolumn{5}{|r|}{} & Pain & 1rstToe - 1rstmetatarsal \\
\hline $6 / \mathrm{F} / 33$ & A.E. 1 session & Pain trophic lesion & 1rstToe - 1rstmetatarsal \\
\hline $7 / \mathrm{M} / 25$ & A.E. 1 session partial resection & Pain trophic lesion & 1rstToe - 2nd phalanx \\
\hline $8 / \mathrm{M} / 31$ & Partial resection & Pain limp trophic lesion & 1rstToe - 1rstmetacarpal - 1rstphalanx \\
\hline $9 / \mathrm{F} / 10$ & A.E. 3 sessions
\end{tabular}

Table 1: Clinical symptoms, localization AVM of Hand and Foot.

NB: A.E. = arterial embolization.

The delay between the initial symptom and the surgery was on average 15 years (7-30). Prior to the surgery, patients had medical treatment (e.g. pain killer, beta blocker drug) and elastic garment.

Clinical examinations provided the following information: pulsatile mass in 6 pts., atrophic soft tissue of distal finger ( $1 \mathrm{pt}$.), soft tissue hypertrophy (3 pts.). No overgrowths on hand and foot were observed. 7 AVMs were located in the bone, $1 \mathrm{AVM}$ on the great toe was associated with AV shunt in cellular space around ankle, and one had diffuse port wine stain of the limb.

\section{Non-invasive Investigations}

Preoperative digital radiographs, Doppler US, CT scan with osseous and vascular reconstructions were obtained on all patients. We do not use anymore preoperative arteriography. Doppler was used to detail the nidus' location where we founded high velocity arteries with low resistance, tortuous veins with arterialized flow and pulsatile flow in the subperiostal space.

By consensus, one radiologist and one surgeon analyzed the extent of involved bone. The common aspects they identified were: Mix lytic sclerotic lesions involving metaphysis, diaphysis and cortical rupture in the metaphysis (Table 2).

\begin{tabular}{|c|c|c|}
\hline Patients & Localization & Intraosseous lesions \\
\hline \multicolumn{3}{|c|}{ Hand } \\
\hline 1 & 1rstmetac - diaphysis metaphysis & Osteolytic/sclerotic lesions \\
\hline 2 & 1rstmetac - metaphysis & Osteolytic foci, cortical rupture \\
\hline 3 & 1rstmetac - metaphysis & Osteolytic foci, cortical rupture \\
\hline 4 & 2dphalanx - metaphysis & Osteolytic foci, cortical rupture \\
\hline 5 & 1rstphalanx - metaphysis & Osteolytic foci, cortical rupture \\
\hline \multicolumn{3}{|c|}{ Foot } \\
\hline 6 & 1rstmetat - diaphysis metaphysis & Osteolytic/sclerotic lesions \\
\hline 7 & 1rstmetat - diaphysis metaphysis & Osteolytic foci, cortical rupture \\
\hline 8 & 2dphalanx - metaphysis & Cortical rupture \\
\hline 9 & 1rstmetat - phalanx metaphysis & Cortical rupture \\
\hline
\end{tabular}

Table 2: Bone lesions, localisation, radiologic datas

NB: metac. $=$ metacarpal, metat. $=$ metatarsal

\section{Open Surgical Treatment}

Nine patients underwent open surgical cementoplasty as we described in our protocol. One patient at the beginning of our experience had an array of occlusion of arterial cortical feeders by subperiostal approach, it was a technical failure, and this patient underwent cementoplasty later. Two patients had, at the same time, limited soft tissue resection. None of them received intra 


\section{Journal of Orthopedics \& Bone Disorders}

operative transfusion. The average duration of surgery was 3 hours (range 2-4). No histological examination was possible.

\section{Postoperative Course}

On the early postoperative period, the most significant benefit was the pain relief. None of the patients exhibited morbidity or delay healing. Control radiographs showed good cement filling in diaphysis, often incomplete in metaphysis but without significant leakage. Until the Doppler control and CT scan, elastic garment, betablocker drug were constant for over 6 months.

\section{Follow-up}

The clinical follow-up at six months showed disappearance of pain and progressive improvement of the function (Tables 3-5).

\begin{tabular}{|c|c|c|c|}
\hline Pain Score & Preoperative number (\%) & Six months number (\%) & Late follow-up number (\%) \\
\hline Minimal / no pain & - & $5(56)$ & $9(100)$ \\
\hline Intermittent pain & $2(22)$ & $4(44)$ & \\
\hline Permanent pain & $7(78)$ & & \\
\hline
\end{tabular}

Table 3: Evolutive status at six months follow-up and last follow-up according to pain score.

\begin{tabular}{|c|c|c|c|}
\hline HAND - 5 patients & $\begin{array}{c}\text { Preoperative } \\
\text { Number (\%) }\end{array}$ & $\begin{array}{c}\text { Six months follow-up } \\
\text { Number (\%) }\end{array}$ & Late follow-up Number (\%) \\
\hline Normal mobility hand digits & $1(20)$ & & $3(60)$ \\
\hline $\begin{array}{c}\text { Limited mobility reduction muscular } \\
\text { strength }\end{array}$ & $2(40)$ & $5(100)$ & $2(40)$ \\
\hline Minimal/no used of hand & $2(40)$ & & \\
\hline \multicolumn{2}{|c|}{ Foot - 4 Patients } & \\
\hline Normal walk & - & $2(50)$ & \\
\hline Difficulty on wearing shoe & $1(20)$ & $2(50)$ & \\
\hline Intermittent/permanent limp & $3(80)$ & & \\
\hline
\end{tabular}

Table 4: Evolutive status at six months and last follow-up according to functional score.

\begin{tabular}{|c|c|c|c|c|}
\hline Patients & Cementoplasty & Complementary procedure & FU months & Residual AVM Inside bone \\
\hline \multicolumn{5}{|c|}{ Hand } \\
\hline 1 & 1rst metacarpal & - & 15 & $\mathrm{No}^{*}$ \\
\hline 2 & 1rst metacarpal & AVM soft tissue resection & 34 & No \\
\hline 3 & 1rst metacarpal & - & 15 & $\mathrm{No}^{*}$ \\
\hline 4 & 2nd phalanx & - & 30 & $\mathrm{No}^{*}$ \\
\hline 5 & 1rst phalanx & - & 10 & $\mathrm{No}^{*}$ \\
\hline \multicolumn{5}{|c|}{ Foot } \\
\hline 6 & 1rst metatarsal & - & 36 & No \\
\hline 7 & 1rst metatarsal & $\begin{array}{l}\text { AVM soft tissue resection complementary } \\
\text { cementoplasty }\end{array}$ & 26 & No \\
\hline 8 & failure & AVM soft tissue resection cementoplasty & 55 & No \\
\hline 9 & $\begin{array}{c}\text { 1rst metatarsal 1rst } \\
\text { phalanx }\end{array}$ & Avm soft tissue resection & 38 & No \\
\hline
\end{tabular}

Table 5: Results (mean Follow-up= 29 months, average 10-55 months).

$*$ = residual microshunts around bone evaluated by Doppler US

Radiographs showed for 7 patients a perfect anatomical result after cementoplasty, 2 had residual intra osseous shunts due to incomplete cementoplasty. Between 6 months and the last follow-up, 2 patients had complementary cementoplasty, one in the metaphysis (Figure 3), the second in diaphysis. 3 patients had resection of soft tissue residual AVM around the initial 


\section{Journal of Orthopedics \& Bone Disorders}

lesion. One of them had resection of AVM of the affected limb but not in relation of AVM of the first toe' AVM.

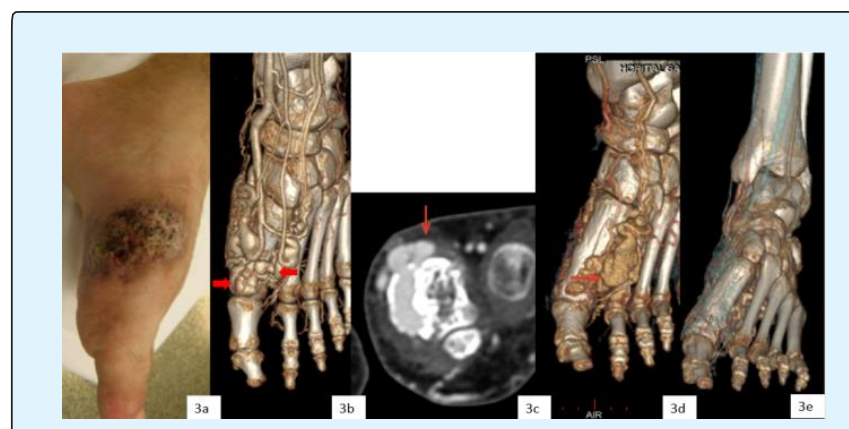

Figure 3: AVM of Foot in 25 years-old man with trophic lesions.

a- Trophic lesions and hemorrhage in the medial part of the forefoot

b- CT scan vascular 3D: AV shunts inside the first metatarsal, ectasic venous drainage in lateral and medial part of the metaphysis (arrow).

c- Initial CT scan osseous reconstruction: venous drainage through a cortical defect in the metaphysis (arrow).

d- Persisting AV shunts in the lateral part of metaphysis after incomplete cementoplasty, residual venous drainage outside bone.

e- Control after 2nd cementoplasty: no residual AV shunt in metaphysis
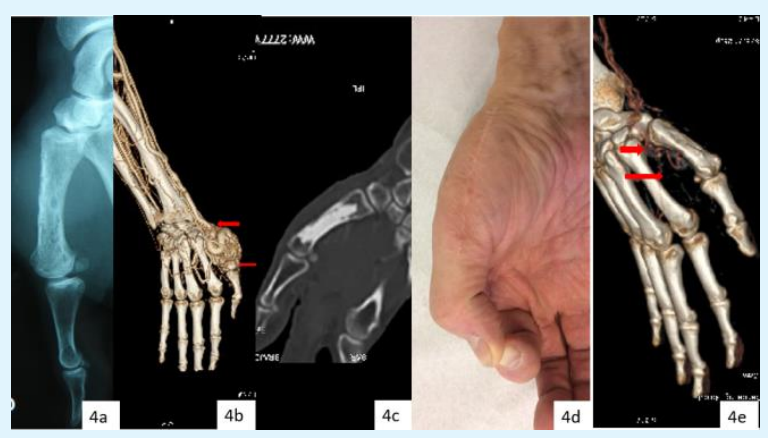

Figure 4: AVM of the 1rst metacarpal of right dominant hand in 30 years-old man.

a- Initial digital radiograph: osteolytic foci and sclerotic lesions in diaphysis and metaphysis.

b- Initial CT scan vascular in 3D with dominant $\mathrm{AV}$ shunt in the first metacarpal (arrow).

c- Radiography after cementoplasty

d- Functional result at 12 months with good mobility of the thumb.

e- Control CT scan at 6 months: residual cortical arteries without residual intraosseous shunt (arrow).
After a mean follow-up of 29 months (range $10-55$ $\mathrm{m}$ ), clinical results (as per Table $\mathrm{V}$ as per below) demonstrated a stable disappearance of the pain, improvement in terms of the hand' mobility, in terms of quality of walk distance by foot. None of the patients had distal amputation. Doppler and CT scan identified residual $\mathrm{AV}$ shunts as per the following: 9 had no residual intraosseous AVshunt (Figure 4), 4 had residual micro AVshunts around bone.

\section{Quality of Life}

At the last follow-up (no patient was lost of follow-up), all patients reported a pain score of 1 (minimal to no pain). Functional scores increased significantly with a better result for foot AVMs and normal ambulation for 4 patients. However, we noted less benefit in the hand due to persisting limited mobility of digit or reduced muscular strength in 2 patients.

All patients were from similar academic or professional background: 2 manual workers, 5 office workers, 1 student, and 1 family occupation, three patients had exercising physical activities. In terms of treatment, 6 had no more treatment but 3 had garment.

\section{Discussion}

Vascular malformations associated with significant bone lesions are rare, and most of the time was reported in craniofacial bones or spine [7,8]. A total of 65 patients with AVMs on hand and foot was identified in our Institution during last four years. 38 of them had AVM of hand or digits, 27 AVM of foot or fore-foot. We identified AVM across 55 patients in the subcutaneous tissue or in cellular space, 10 showed intraosseous AVM on CT scan persisting after recurrent embolization (5 patients), and 2 of them after partial surgery. In 1 patient, cementoplasty was deleted due to trophic lesions. The design of a control group is difficult due to rareness of this pathology and the diversity of anatomical lesions.

\section{Vascular Malformations and Bone Involvement}

The ISSVA classification can be applied to vascular bone lesions, as well as venous, lymphatic, and arteriovenous malformations.

Reports of AVM 'bone are rarely published [5,6,9]. Different radiograph aspects showed similarities on osteolytic lesions and disruption of cortical dominant in the metaphysis area, or small foci with sclerotic lesions dominant in diaphysis. Distinction should be made 


\section{Journal of Orthopedics \& Bone Disorders}

between reactive bone changes (cortical thickening, or depression, leg length discrepancy), which have been excluded from this study, and true intra osseous density changes (Figure 4).

The classifications of AVM's subgroup on hand and foot depended on symptoms [3], vessels [1,2] or involved tissue [4]. Classifications based on the tissue involved by the AV shunt could be a more precise approach (soft tissue, intra articular, intra osseous AVM) [10-12]. In our series, we included single intra osseous lesions or with limited soft tissue lesion.

\section{Investigations}

The quality of investigations can be more precise when analyzing the tissular area of AVshunt with radiograph, Doppler and CT scan. As such, the radiograph identified skeletal density changes; the Doppler points the affected area with feeder arteries with high flow, while the CT scan gave the best anatomical data identifying the nidus' location and structural changes of bone.

\section{Arterial/Venous Embolization - Percutaneous Sclerotherapy}

Arterial embolization was the first line for a AVMs treatment. The goal in any AVM embolization is to occlude the nidus. Different materials have been used but they didn't provide better results. Ethanol embolization performed by transarterial approach with additional direct puncture is an alternative [10-12]. However reports showed that 10 to $30 \%$ of complications were due to tissue necrosis and neuropathy [4].

Occlusion of the venous drainage by transvenous embolization, completed with sclerotherapy with ethanol is another approach, but occlusion of nidus is always theoretical.

Our goal was not to occlude feeding arteries or venous drainage (often numerous), but to identify tissular location of nidus by CT scan and to occlude it by cementoplasty in bone.

\section{Cementoplasty in Intra osseous AVM}

Percutaneous cementoplasty has been introduced to treat osteolytic lesions in skeletal system [13].

The effectiveness of percutaneous cementoplasty in treating painfull osteolytic bone metastases in and outside the spine is well documented $[9,14,15]$. This restricted procedure to osteolytic bone disease was widely used in vascular malformation such lymphangiomatosis with large cyst degeneration [9]. At the opposite, AVMs bone lesions were made of small lytic cavities with thickened irregular trabecular patterns and virtual marrow cavity explaining the difficulty of percutaneous procedures.

For the last 4 years, surgical cementoplasty was offered as a treatment of hand or foot AVMs, and bone lesions. CT scan with multi-planar osseous reconstruction evaluated the lesion type: osteolytic, sclerotic or mixed, and the extension range with or without cortical breakthrough. In this serie, dominant lesions were in the metaphysis of bone.

The most effective technique appeared to be the surgical cementoplasty with opening the bone. Complete occlusion of cortical defects (feeder cortical arteries, venous drainage) needed to drill the medulla to obtain a good space for application homogeneously cement.

Moreover, cementoplasty simplified complementary surgical resection of residual soft tissue AVM.

No adverse event was observed in this study. Control radiographs after the procedure demonstrated the good deposition of cement in the diaphysis and metaphysis areas in most cases, no extensive leak around the bone and good morphological characteristics of bone. Nevertheless cementoplasty is not today an established treatment for intraosseous AVMs.

Cementoplasty of intra osseous AVM can be indicated where a precise diagnosis can be made. Diagnosis needs to point out that the osseous lesions' research to the vicinity of AVM area especially to the distal part of limb. Digital radiographs, CT scan focus on alterations of structure of bone, while the arteriography, which never locates the nidus into specific tissue.

Different clinical and anatomical subgroups can be discussed, as per below:

- Treating minimally symptomatic patients to prevent evolutive bone lesions: few morbidities of cementoplasty could be an element to provide this procedure early on. Nevertheless, surgical resection of soft tissue or embolosclerotherapy cannot be proposed in such situation due to high level of complications (40\%) [12], or digital /hand amputations (22\%) [3].

- Patients with located intra osseous AVM, persisting symptoms after medical treatment or embolization are scheduled for cementoplasty before appearance of trophic lesions. 


\section{Journal of Orthopedics \& Bone Disorders}

- Associated soft tissue AVM is a third group. In our experience, cementoplasty should be the first step. Following this, surgical resection of involved residual soft tissue is easier; these lesions were often developed around bone.

- Multi focal intra osseous AVM should not be an exception. Cementoplasty on different area could be completed at the same time to avoid progressive evolution of a second nidus.

At last, imaging control of all procedures is needed to document results and to compare them. In most of the published reports $[10,12]$ results were reported on clinical records and with a large loss of follow-up. We reported a short serie on hand and foot AVM with for all patients Doppler and CT scan controls.

\section{Conclusion}

Targeted diagnosis of AVM permits specific therapeutic procedures helpful in decision-making. Open surgical cementoplasty is a therapeutic option with few complications and durable effect on pain and functional result. Nevertheless, cementoplasty is an invasive approach based on a retrospective study made in a single center, and conclusions are restricted by the short followup for this pathology.

\section{Ethical Standards}

Conflict of Interest: The authors declare that they have no conflict of interest

Sources of Funding: This research did not receive any specific grant from funding agencies in the public, commercial, or not for profit sectors.

Informed Consent: Informed consent was obtained from all individual participants included in this study.

Ethical Approval: All procedures performed in this study involving human participants were in accordance with the clinical standards of our institution and with the 1964 Helsinki declaration and its later amendments or comparable ethical standards.

\section{References}

1. Baumgartner I, Yakes WF (2014) Interventional treatment of arteriovenous malformations. Gefasschirurgie 19: 325-330.

2. Yakes WF, Hugueno M, Yakes A, Continenza A, Kammer R, et al. (2016) Percutaneous embolization of arteriovenous malformations at the plantar aspect of the foot, J Vasc Surg 64(5):1478-1482.

3. Al-qattan MM, Murray KA, El-shayeb A (2006) Arteriovenous vascular malformations confined to the hand: an algorithm of management based on a new classification. Journal of Hand Surgery 31(3): 266-273.

4. Park HS, Do YS, Park KB, Kim DI, Kim YW, et al. (2011) Ethanol embolotherapy of hand arteriovenous malformations. J Vasc Surg 53(3): 725-731.

5. Madhusudhan KS, Sharma R, Kandpal H, Kumar A, Gamanagatti S, et al., (2014) A rare case of combined soft tissue and intraosseous arteriovenous malformations of hand with diffuse periostal elevation: imaging appearances. BJR 82(983): e21924.

6. Dan VN, Akhmedov BG, Krupochkin SN, Sapelkin SV, Tsygankov VN, et al. (2015) Use of polymethylmetacrylate in treatment of arteriovenous angiodysplasia with bone lesions. Angiol Sosud Khir 21(3): 153-158.

7. Breugen CC, Haus M, Breugen SJM, Schaap GR, Van der Horst AM, et al. (2003) Vascular malformations of the lower limb with osseous involvement. J Bone Joint Surg Br 85(3): 399-405.

8. Bruder E, Perez-atayde AR, Jundt G, Alomari AI, Rischewski J, et al. (2009) Vascular lesions of bone in children,adolescents and young adults. A clinicopathologic reappraisal and application of ISSVA classification, Virchows Arch 454(2): 161-179.

9. Wallace MJ, Ross M (2005) Bone lymphangiomatosis: treatment with percutaneous cementoplasty. Spine 30(12): E336-E3399.

10. Hyun D, Do YS, Park KB, Kim DI, Kim YW, et al. (2013) Ethanol embolotherapy of foot arteriovenous malformations. J Vasc Surg 58(6): 1619-1626.

11. Park UJ, Do YS, Park KB, Park HS, Kim YW, et al. (2012) Treatment of arteriovenous malformations involving the hand, Annals of Vascular Surgery 26(5): 643-648.

12. Guillet A, Connault J, Perrot P, Perret C, Herbreteau D, et al. (2016) Early symptoms and long term clinical outcomes of distal limb's cutaneous arteriovenous 


\section{Journal of Orthopedics \& Bone Disorders}

malformations. A retrospective multicenter study of 19 adult patients. JEADV 30(1): 36-40.

13. Galibert P, Deramond H, Rosat P, Legars D (1987) Preliminary note on the treatment of vertebral angioma by percutaneous acrylic vertebroplasty. Neurochirurgie 33(2): 166-168.

14. Ianessi A, Amoretti N, Marcy PY, Sedat J (2012) Percutaneous cementoplasty for the treatment of extraspinal painfull bone lesion, a prospective study. Diagnostic and interventional imaging 93(11): 859870.

15. Cazzato RL, Buy X, Grasso RF, Luppi G, Faiella E, et al. (2015) Interventional radiologist's perspective on the management of bone metastatic disease, EJSO 41(8): 967-974. 